\title{
Bell, Whistles, and Leak Profiles
}

Positive airway pressure (PAP) therapy is almost universally effective in treating obstructive sleep apnea. The biggest obstacle in treating obstructive sleep apnea is getting patients to use the PAP device.

The term "adherence" is gaining favor over the term "compliance." The definition of PAP adherence varies, but the generally accepted (and somewhat arbitrarily chosen) definition is $\geq 4$ hours per night. PAP adherence rates vary widely. A large study in the United Kingdom found a 10 -year adherence rate of $70 \% .{ }^{1}$ Another study that followed a non-insured population in the United States found an adherence rate of $48 \%$, but the rate dropped to $30 \%$ if the patients who did not follow up in clinic were considered non-adherent. ${ }^{2}$ Regardless of the population studied, inadequate adherence is a big problem.

Research on adherence can be divided into 2 broad categories: interventions that increase adherence (eg, mask changes, auto-titrating devices vs fixed pressure devices), and predictors of non-adherence (eg, age, severity of obstructive sleep apnea). Research on predictors of non-adherence will help clinicians identify individuals who may not adhere to PAP therapy, but that knowledge will be useful only if we can improve adherence. Unfortunately, little progress has been made on this front.

As long-term adherence patterns are established within the first 7 days of PAP therapy, early intervention is important. ${ }^{3}$ Behavioral and non-behavioral interventions have been studied. The most effective interventions are behavioral,, 45 but these interventions are time and labor intensive for both the patient and the practitioner. Nonbehavioral interventions include changing masks or improving mask fit, heated humidification, using a bi-level (BiPAP) device or a flexible bi-level device (eg, C-flex, Respironics, Pittsburgh, Pennsylvania), or using an auto-titrating device. Some of these interventions have shown early promise in selected groups, but others have shown no advantage. ${ }^{6}$

Advances in device technology are not limited to pressure modification. Most current PAP devices record several variables in addition to hours used per night and number of nights used. Adherence data over the last 8 months from a patient in our clinic yielded a 15-page report that included values such as "average vibratory snore index," "average maximum leak," "average 90\% leak," and "average max leak." A full hour-by-hour report of each night was also available, in a hypogram-like graph. Intuition and anecdotal evidence indicate that a high level of leak requires some sort of intervention, but beyond that it is unclear what all these data mean.

See the Original Study on Page 591

In this issue of the Journal, Baltzan et $\mathrm{al}^{7}$ describe 2 types of leak: serrated leak and continuous leak. They prospectively followed 35 patients, downloaded adherence data, manually analyzed one week of leak data from each patient to determine the percentage of time the patients spent in the 2 leak states, and administered adverse-effects questionnaires.

The inter-rater reliability with their leak-scoring method was good. The machine-reported levels of " $90 \%$ leak" and "average leak" correlated modestly with the percentage of time in continuous and serrated leak. Respironics and ResMed did not respond to a request for clarification of these values. The adverse effects (mouth air leak, dry mouth, morning stuffy nose, rhinorrhea, and headache) correlated with percentage time in serrated leak $(P<.01)$, whereas adherence did not. Adherence was lower in the highest quartile of percentage time in continuous leak, although Baltzan et al postulate that that may be a chance finding. Regardless, adherence was good in the highest quartile and the lower 3 quartiles of percentage time in continuous leak (6.66 $\pm 1.72 \mathrm{~h} /$ night vs $5.28 \pm 2.24 \mathrm{~h} /$ night).

How does this study help interpret the mountain of leak data that now accompanies most adherence downloads? Although it is an interesting proof-of-concept article, their method will not help much until further study is performed. The majority of patients have adverse effects from PAP therapy, but the adverse effects do not seem to be a deterrent to adherence. ${ }^{3}$ In addition, simple interventions such as mask adjustment, heated humidification, nasal steroids, and education convert $24 \%$ of non-adherent patients to adherent patients after one week, ${ }^{8}$ and these can be performed without analyzing leak data.

Since both types of leak correlate with a high level of machine-reported leak, a manual inspection of the leak graph is necessary to determine which kind of leak the patient is experiencing. It is uncertain whether the type of leak matters. The patient population in the Baltzan et al study was selected because they were likely to be highly adherent to therapy, and indeed they were. The type of 
leak may correlate with adherence in a more general population. Studies are needed that show which interventions address each type of leak, and if those interventions convert a non-adherent patient to an adherent patient. Such findings could then be applied to the $75 \%$ of patients who do not respond to simple interventions. ${ }^{8}$ Some research also suggests that there is a drop in adherence after 3 months of PAP, ${ }^{9}$ and leak profile inspection could guide interventions in that group.

Although no solid conclusions can be drawn from the Baltzan et al study, ${ }^{7}$ it provides a starting point for interpreting the overwhelming amount of data that now comes with each adherence report. One day clinicians may use the data to improve adherence, which is simultaneously the biggest impediment to the treatment of sleep-disordered breathing and the most frustrating aspect of practicing sleep medicine.

Stephen W Littleton MD

Department of Pulmonary and Critical Care Medicine Cook County Hospital Chicago, Illinois

The author has disclosed a relationship with Respironics.

Correspondence: Stephen W Littleton MD, Department of Pulmonary and Critical Care Medicine, Cook County Hospital, 1900 W Polk Street, Room 1416, Chicago IL 60612. E-mail: slittleton@cchil.org.

DOI: $10.4187 /$ respcare. 01326

\section{REFERENCES}

1. Kohler M, Smith D, Tippett V, Stradling JR. Predictors of long-term compliance with continuous positive airway pressure. Thorax 2010; 65(9):829-832

2. Joo MJ, Herdegen JJ. Sleep apnea in an urban public hospital: assessment of severity and treatment adherence. J Clin Sleep Med 2007; 3(3):285-288.

3. Weaver TE, Grunstein RR. Adherence to continuous positive airway pressure therapy: the challenge to effective treatment. Proc Am Thorac Soc 2008;5(2):173-178.

4. Hoy CJ, Vennelle M, Kingshott RN, Engleman HM, Douglas NJ. Can intensive support improve continuous positive airway pressure use in patients with the sleep apnea/hypopnea syndrome? Am J Respir Crit Care Med 1999;159(4 Pt 1):1096-1100.

5. Richards D, Bartlett DJ, Wong K, Malouff J, Grunstein RR. Increased adherence to CPAP with a group cognitive behavioral treatment intervention: a randomized trial. Sleep 2007;30(5):635-640.

6. Smith I, Lasserson TJ. Pressure modification for improving usage of continuous positive airway pressure machines in adults with obstructive sleep apnoea. Cochrane Database Syst Rev 2009;(4): CD003531.

7. Baltzan MA, Dabrusin R, Garcia-Asensi A, Sully JL, Parenteau M, Tansimat $\mathrm{G}$, et al. Leak profile inspection during nasal continuous positive airway pressure. Respir Care 2011;56(5):591-595.

8. Ballard RD, Gay PC, Strollo PJ. Interventions to improve compliance in sleep apnea patients previously non-compliant with continuous positive airway pressure. J Clin Sleep Med 2007;3(7):706-712.

9. McArdle N, Devereux G, Heidarnejad H, Engleman HM, Mackay TW, Douglas NJ. Long-term use of CPAP therapy for sleep apnea/ hypopnea syndrome. Am J Respir Crit Care Med 1999;159(4 Pt 1): 1108-1114. 